\title{
O ensino de leitura em dissertações do PROFLETRAS: radiografia de propostas de intervenção na educação básica
}

\author{
Reading teaching in PROFLETRAS dissertations: radiography of \\ intervention proposals in basic education
}

\author{
Ananias Agostinho da Silva * \\ ananias.silva@ufersa.edu.br \\ Universidade Federal Rural do Semi-Árido
}

\begin{abstract}
RESUMO: O objetivo deste trabalho é realizar uma radiografia das propostas de intervenção de ensino de leitura desenvolvidas no âmbito do Programa de Mestrado Profissional em Letras, a fim de identificar os gêneros textuais trabalhados, os anos escolares, as perspectivas teórico-metodológicas de base das propostas e os produtos didáticos desenvolvidos. Para isso, realizamos um levantamento exaustivo das dissertações desenvolvidas no programa com base em pesquisa documental, de caráter descritivo e abordagem mista. O corpus é constituído de 100 dissertações e a análise guiou-se por um protocolo elaborado conforme os objetivos da pesquisa. Os resultados apontaram para a predominância dos gêneros literários nas propostas de intervenção, ainda que se possa visualizar uma grande variedade de gêneros encontrados pertencentes a domínios como o publicitário, o midiático, o jornalístico, o instrucional, o de lazer e o interpessoal. Ademais, revelaram que o procedimento da sequência didática (da Escola de Genebra) é muito utilizado pelos professores para a elaboração de suas propostas de intervenção, desenroladas mais recorrentemente no $6^{\circ}$ e no $9^{\circ}$ ano do Ensino Fundamental.
\end{abstract}

PALAVRAS-CHAVE: PROFLETRAS. Ensino de leitura. Intervenção.

ABSTRACT: The objective of this paper is to carry out an x-ray of the reading teaching intervention proposals developed under the Professional Master's Program in Letters, in order to identify the genres worked, school years, the theoretical-methodological perspectives of the proposals and the didactic material developed. It carries out an exhaustive survey of the dissertations developed in the program based on documentary research, of a descriptive character and mixed approach. The corpus consists of 100 dissertations and the analysis was guided by a protocol designed according to the research objectives. The results point to the predominance of literary genres in the intervention proposals, although it is possible to visualize a wide variety of genres found. They also reveal that the didactic sequence procedure (from Geneva school) is widely used by teachers to prepare their intervention proposals, developed more frequently in the 6th and 9th grades of the Middle School.

KEYWORDS: PROFLETRAS. Reading teaching. Intervention.

* Doutor em Estudos da Linguagem. Professor do Programa de Pós-Graduação em Ensino (POSENSINO), da associação ampla entre UFERSA, IFRN e UERN. Professor do Programa de Mestrado Profissional em Letras (PROFLETRAS), da Unidade de Pau dos Ferros, UERN. Professor do Departamento de Ciências Humanas, do Campus de Angicos, da UFERSA. 


\section{Introdução}

O que se diz sobre a leitura no Brasil? Uma simples busca na internet revela resultados que figuram uma realidade problemática do país. Mesmo fugindo do equívoco da generalização do senso comum, de que o Brasil é um país de não leitores, não podemos levianamente ignorar os resultados apontados a partir de pesquisas sólidas, desenvolvidas por órgãos de credibilidade reconhecida mundialmente, como o Instituto Pró-Livro. Em 2019, o Pró-Livro evidenciou que quase metade da população brasileira, 44\%, não possui o hábito de ler livros. Naquele mesmo ano, um levantamento realizado pela Unesco também demonstrou que somente $3,6 \%$ dos alunos de escolas públicas do Brasil concluem o Ensino Fundamental com habilidades avançadas de leitura.

Não parece ser descabida, então, a representação construída sobre o Brasil a respeito da leitura. Toda a história de desenvolvimento do país, especialmente no que se refere à educação, em termos, é excludente e limitada, até mesmo na atualidade, quando se propõe democrática e como um direito inalienável. Já no primeiro século do Novo Mundo, a educação jesuíta era ideologicamente marcada pelo sentimento religioso que, por um lado, segregava os alunos - distinguindo os filhos dos colonos, educados nos colégios, dos filhos dos índios, educados nas aldeias - e, por outro, limitava o conhecimento com um currículo direcionado ao catecismo. Se a Reforma Pombalina excomungou jesuítas da colônia, desmantelou o aparelho educacional, de forma que as aulas régias quase em nada contribuíram para a educação dos brasileiros. Mesmo que, no período imperial, a oferta da educação primária gratuita para os cidadãos tenha sido constitucionalmente assegurada, milhares de brasileiros nunca conseguiram ser alfabetizados - os escravos não tiveram esse direito garantido nem teoricamente. De igual modo, na primeira república, o excesso de tecnicismo empenhado na oferta de uma educação profissional apenas qualificou uns para o mercado de trabalho. No estado de exceção, a ingerência dos militares tornou a educação ainda mais obscurantista: a censura da leitura é o maior exemplo disto. $\mathrm{Na}$ nova república, a promulgação da Constituição Federal assegurou a educação enquanto direito fundamental de todos, mas, apesar de expressivas iniciativas políticas, não se conseguiu assegurá-lo em plenitude. Hoje, quando vivemos novas formas de censura na educação, é imperativo discutir novas alternativas para o ensino de leitura no país. 
Se "somos todos feitos do que os outros nos dão: primeiro nossos pais, depois aqueles que nos cercam" (TODOROV, 2009, p. 23-24), o elevado número de não leitores em nosso país parece ser resultado daquilo que não Ihes dão. O aprendizado da leitura depende sistematicamente de ensino. Não se trata de habilidade que o indivíduo desenvolve a partir de competência inata, já que o papel do outro é insubstituível. Além disso, demanda acesso aos bens culturais, ou seja, não é possível aprender a ler e desenvolver o gosto ou hábito de leitura sem livros, sem acesso a bens culturais e sem condições infraestruturais para isso.

No Brasil, as políticas públicas de acesso ao livro ainda são limitadas, pois alcançam prioritariamente estudantes de escolas públicas e ainda de modo insuficiente, já que muitas delas são desenvolvidas em grandes centros urbanos. Assim, por exemplo, apesar de o Programa Nacional Biblioteca da Escola, vigente desde 1997, buscar promover o hábito de leitura e ampliar o acesso à cultura e à informação nas escolas públicas a partir da distribuição de acervos de obras, para o Anuário Brasileiro da Educação Básica, em 2020, apenas 45\% das escolas públicas da Educação Básica do país possuíam bibliotecas ou salas de leitura. Esse dado ilustra como as políticas públicas de acesso ao livro e de incentivo à leitura no país ainda têm se revelado pouco eficientes para atender à demanda.

$\mathrm{Na}$ asserção de Todorov (2009), são os pais os primeiros que ensinam a respeito das coisas da vida, inclusive sobre a leitura. Longe de um determinismo de herança genética nos prognósticos dos indivíduos, não podemos ignorar a influência que os pais exercem na formação cultural dos seus filhos. Na pesquisa promovida pelo Pró-Livro anteriormente citada, já se faz alerta para uma possível associação entre a formação de novos leitores e as experiências de seus pais com a leitura. Nesse ponto, é também importante lembrar Paulo Freire, quando dizia que "[...] a leitura do mundo precede sempre a leitura da palavra e a leitura desta implica a continuidade da leitura daquele" (2006, p. 20). Em alguma medida, esse movimento dialógico sugere a influência, ainda que não determinante, mas crucial, do seio familiar no aprendizado da leitura, de maneira que, em famílias cujos pais cultivam experiências positivas com a leitura, há uma grande probabilidade de os filhos serem motivados a desenvolverem gosto e hábito pela prática.

Se os pais são esses primeiros agentes, os professores ocupam o segundo lugar nesse processo - a hierarquia sugere apenas cronologia da vivência humana. No processo de escolarização da leitura, os professores assumem importância 
relevada: são responsáveis por elaborar estratégias de ensino que busquem potencializar a formação de alunos leitores, mesmo diante de dificuldades, como a falta de políticas públicas efetivas de incentivo à leitura, de acesso aos bens culturais; o histórico de defasagem da escolaridade dos pais; as condições socioeconômicas dos alunos; a precariedade de seus salários e das condições de trabalho. Ora, formar leitores capazes de compreender as diferentes práticas de linguagem que decorrem da interação viva-ativa do leitor com textos orais, escritos e até multissemióticos de gêneros variados, segundo preconiza a Base Nacional Comum Curricular, é uma demanda emergente na sociedade atual. Portanto, alcançar satisfatoriamente esse objetivo compreende um desafio enfrentado pelos professores das escolas públicas da Educação Básica brasileira.

Uma alternativa possível é a formação continuada. No Brasil, diversos programas voltados à formação de professores têm potencialmente contribuído para a qualificação profissional e, com efeito, para a qualidade da Educação Básica ofertada. Referente ao ensino de leitura, dentre tantos outros, podemos mencionar o Programa de Mestrado Profissional em Letras (PROFLETRAS), direcionado aos professores de língua portuguesa com formação inicial em Letras e em exercício nas escolas públicas do país. Alguns dos resultados obtidos já acenam para as contribuições desse programa: diversas dissertações defendidas e propostas exitosas de intervenção em sala de aula, produtos didáticos variados etc.

No caso em específico do ensino de leitura, nosso objetivo, nesse trabalho, é realizar uma radiografia das propostas de intervenção pedagógica desenvolvidas na Educação Básica, buscando, pois, identificar os gêneros trabalhados, as perspectivas teórico-metodológicas que fundam as propostas e os produtos didáticos desenvolvidos. Dessa forma, como resultado, esperamos cotejar as repercussões do programa para o ensino de leitura no Brasil como tentativa de redimensionar o atual quadro de desinteresse dos sujeitos por esta habilidade tão imprescindível na contemporaneidade.

Para tanto, além desta primeira seção, o presente trabalho encontra-se estruturalmente assim configurado: a segunda seção recupera o contexto de criação do PROFLETRAS como programa em rede, balizando especificidades de um mestrado profissional, apresentando os objetivos do programa, a sua área de concentração e as linhas de pesquisa. A terceira seção focaliza o percurso metodológico traçado para a coleta e a seleção dos dados e o protocolo de análise 
perseguido. A quarta seção apresenta a análise dos dados, isto é, construímos uma radiografia das propostas de intervenção do PROFLETRAS voltadas para o ensino de leitura. Finalmente, realizamos discussão dos resultados e considerações finais acerca do trabalho.

\section{Sobre o PROFLETRAS}

Diversos programas de pós-graduação têm investido na oferta de cursos de mestrado profissional no Brasil nos últimos dez anos. Todavia, mesmo que essa expansão tenha se acentuado nesse período, é já desde o final da década de noventa do século XX que a Coordenação de Aperfeiçoamento de Pessoal de Nível Superior (CAPES) reconhece e regulamenta esse tipo de curso em nível de pós-graduação stricto sensu (Portaria $\mathrm{n}^{\circ}$. 80/1990). Mas, mesmo antes disso, alguns cursos de mestrado já apresentavam uma perspectiva muito mais profissional do que acadêmica propriamente. Isso reforçou a necessidade de cursos específicos, direcionados para a existência de uma pós-graduação mais a serviço da sociedade.

De fato, esse é justamente um traço distintivo do mestrado profissional: a aplicação do conhecimento técnico-científico da universidade para o mercado. Ou seja, diferentemente de um curso de mestrado acadêmico, que visa o aprofundamento de conhecimentos ou de técnicas de pesquisa científica, tecnológica ou artística, os cursos de mestrado profissional pretendem a formação continuada de sujeitos oriundos do mercado de trabalho aspirando à elaboração de novas técnicas e novos processos de produção. Nesse contexto, o mestrado profissional é um título terminal, isto é, não projeta para o pesquisador a construção de uma carreira acadêmica, dando sequência ao mestrado num curso de doutorado, por exemplo, ou estimulando a atuação contínua em grupo ou laboratório de pesquisa especializado - ainda que isso não seja impossível. É que o foco do mestrado profissional é muito mais inserir o sujeito na pesquisa, fazendo com que ele compreenda o processo de pesquisar a partir de experiências de sua prática profissional, de maneira a reconhecer no seu trabalho as situações que podem ser objetos de investigação para melhoramento futuro.

Ao contrário do que equivocadamente se pensa, o mestrado profissional não pode ser encarado como um curso stricto sensu facilitado ou mesmo como se apenas correspondesse a um curso de especialização ou de aperfeiçoamento do tipo lato 
sensu. O mesmo rigor empregado na avaliação de cursos de mestrado acadêmico ocorre com os cursos de mestrado profissional. A CAPES avalia o funcionamento do curso, as condições de oferta, a produção de professores e de alunos, a qualidade das pesquisas, o impacto social dos resultados, dentre outros critérios, com a mesma intensidade, não fazendo, nesse sentido, distinção entre essas duas modalidades de mestrado.

No caso do Programa de Mestrado Profissional em Letras (PROFLETRAS), o curso de mestrado é ofertado em rede nacional, no contexto da Universidade Aberta do Brasil. Com sede na Universidade Federal do Rio Grande do Norte (UFRN), instituição proponente, o programa conta com a participação de diversas Instituições de Ensino Superior (IES) de todas as regiões do país. O programa conta com pelo menos 42 universidades. Conforme regimento interno, o curso visa à capacitação de docentes de Língua Portuguesa para exercício da docência no Ensino Fundamental, com o intuito de contribuir para a melhoria da qualidade do ensino no país.

Para atingir seu objetivo, a organização curricular do programa é dada pela área de concentração Linguagens e Letramentos. Entende-se que a formação do professor que atua na disciplina de Língua Portuguesa no Ensino Fundamental deve ser aprofundada nos estudos da linguagem para que se possa construir uma posição madura intelectualmente para lidar com a realidade linguística do aluno nos mais variados níveis. Além disso, considera que a complexidade própria da linguagem com sua dinamicidade e plasticidade evidenciadas nos dias atuais, sobretudo demanda do professor a atualização de conhecimentos e de novas práticas pedagógicas que vão ao encontro das reais necessidades de aprendizagem dos alunos frente às diferentes linguagens utilizadas no cotidiano.

Esta área de concentração reúne duas linhas de pesquisa:

a) Teorias da Linguagem e Ensino: pesquisas desenvolvidas nesta linha devem buscar retomar as noções de língua e linguagem, a partir de diferentes perspectivas teóricas, para compreender os níveis de funcionamento da linguagem, os processos fonológicos que interferem na aquisição da leitura e da escrita, os domínios de produção de textos e discursos, os graus de arbitrariedade e de iconicidade das linguagens, as identidades e os seus processos de construção, a dialogicidade inerente a todos esses processos e a formação do leitor.

b) Leitura e Produção Textual: diversidade social e práticas docentes: pesquisas que se voltam para a compreensão da educação inclusiva ou que focalizam aspectos 
como as causas do fracasso escolar, a configuração de transtornos de linguagem e também de aprendizagem, o letramento da comunidade surda, a produção de material instrucional orientado, dentre outras abordagens.

Essa amplitude de possibilidades de pesquisa que a área de concentração apresenta já se revela na quantidade de dissertações defendidas, de produtos pedagógicos publicados, nos diversos textos publicados em revistas, capítulos de livros e livros. Nessas duas linhas de pesquisa, até o ano de 2019, a partir de levantamento realizado no site do programa, foram publicadas 2412 dissertações em universidades de todo o país - com destaque para a Universidade do Estado do Rio Grande do Norte (UERN), que, até esse período, havia publicado 162 dissertações.

Diversas dessas dissertações tratam sobre o ensino de leitura, sobretudo na perspectiva da formação do leitor. As abordagens teórico-metodológicas são as mais variadas no leque dos estudos da linguagem, inclusive assentando interfaces produtivas com abordagens da educação, ciências da cognição, das artes cênicas e outras. O levantamento dessas abordagens e a reflexão acerca das propostas de intervenção desenvolvidas nessas pesquisas se apresentam no tópico que segue.

\section{Metodologia}

Do ponto de vista dos seus objetivos, esta investigação, cujos resultados são apresentados neste trabalho, pode ser caracterizada como sendo uma pesquisa descritiva, pois descrevemos os fatos observados sem fazer interferências neles, ou seja, visamos à construção de uma radiografia das propostas de ensino de leitura desenvolvidas no PROFLETRAS, mas não Ihes atribuímos juízo de valor. Do ponto de vista dos procedimentos técnicos, trata-se de uma pesquisa documental, pois as dissertações, ao menos no conjunto de critérios por nós traçados, ainda não receberam tratamento analítico. Do ponto de vista da abordagem, caracteriza-se como uma pesquisa mista, porque recorremos a instrumentos quantitativos, mas priorizamos a discussão indutiva dos fenômenos observados nos dados, de maneira a construir significados.

Do universo de 2412 dissertações já publicadas pelos mestrandos do PROFLETRAS no período de 2015-2019, buscamos filtrar, por meio de uma busca realizada no site desse programa, aquelas que tratam especificamente sobre o ensino de leitura. Assim sendo, a partir do descritor ensino de leitura, encontramos 671 
dissertações com foco no ensino de leitura, na formação de leitores ou ainda realizando uma interface entre esses e outros temas, como o ensino de escrita e de oralidade, por exemplo. Esse dado revela um percentual significativo $(27,8 \%)$ de todo o quadro de dissertações já desenvolvidas no PROFELTRAS, considerando a diversidade de temáticas que as duas linhas de pesquisa do programa comportam.

Após a coleta de 671 dissertações de mestrado acerca do tema ensino de leitura (através de download no site oficial do programa), fundamentamo-nos na metodologia da análise de conteúdo (BARDIN, 2011) para o tratamento de dados. Assim, num primeiro momento, procedemos à composição do corpus da pesquisa. Em seguida, considerando a exaustiva quantidade de material textual primeiramente coletado, buscamos selecionar uma amostra que, satisfatoriamente, representasse todo o universo de dados. Desse modo, e dado o grande número de dados obtidos, a partir de sorteio simples, selecionamos 100 dissertações para a análise, constituindose, portanto, o corpus da pesquisa. Entendemos esse número de textos como sendo representativo de toda a quantidade de dissertações coletadas acerca do ensino de leitura, de maneira que a análise desse material permitiu-nos realizar interpretações estendidas para todos os demais textos.

Em seguida, foi realizado o trabalho de tabulação e codificação dos dados constitutivos do corpus. Esses dados foram tabulados em um quadro com as seguintes informações: número de ordem dos textos (01 a 100), título da dissertação, instituição de origem, ano de publicação e código de identificação. Dada a extensão do material e as limitações de espaço deste texto, preferimos não reproduzir aqui o quadro referido. As dissertações foram codificadas da seguinte maneira: DPF01, onde DPF refere-se à dissertação do PROFLETRAS e 01 a ordem numérica dos textos selecionados para a constituição do corpus.

$\mathrm{Na}$ sequência, orientamo-nos por um protocolo de análise elaborado a partir dos nossos objetivos específicos, ambicionando a construção de uma radiografia das propostas de ensino de leitura desenvolvidas no âmbito do PROFLETRAS:

a) Identificação dos gêneros textuais sugeridos ou trabalhados;

b) Identificação de anos escolares de turmas onde se desenvolveram as propostas;

c) Identificação das abordagens teórico-metodológicas que fundamentaram a elaboração e a aplicação das propostas de intervenção;

d) Descrição e análise da organização didático-pedagógica das propostas; 
e) Análise e reflexão sobre os efeitos das propostas na Educação Básica, sobretudo no que diz respeito ao ensino de leitura.

O rigor metodológico do protocolo de análise foi substancial para a construção de uma radiografia, ou seja, para o exame das partes constitutivas desse organismo em análise. Se, numa clínica médica, a radiografia permite construir representação das dimensões de estruturas superpostas, no nosso caso, a metáfora da radiografia justifica-se pela apreciação cautelosa dessas propostas de ensino de leitura.

\section{Análise dos dados}

As propostas de ensino de língua portuguesa desenvolvidas no âmbito do PROFLETRAS organizam-se, quase sempre, em torno de um gênero textual - ainda que a terminologia se altere a depender da abordagem teórico-metodológica adotada. Esse procedimento segue de perto as orientações de documentos oficiais reguladores do ensino no Brasil, como os Parâmetros Curriculares Nacionais (PCN) e o documento da Base Nacional Comum Curricular (BNCC): o texto é a unidade do ensino de língua portuguesa, e todo texto se organiza dentro de determinado gênero em função das intenções comunicativas; portanto, os gêneros textuais são o objeto de ensino para as práticas de leitura, produção e análise linguística e semiótica nas aulas de língua portuguesa. Além disso, o trabalho com os gêneros textuais na escola é fundamentalmente necessário para a formação dos alunos como cidadãos, já que a interação plena nas mais diversas áreas de atividade humana exige grau de letramento que se alcança pelo domínio efetivo dos variados modelos de enunciados que atendem às nossas necessidades de comunicação. Assim sendo, para alcançar o objetivo deste trabalho, buscamos, primeiramente, identificar os gêneros textuais sugeridos ou trabalhados nas propostas de intervenção em práticas de ensino de leitura no PROFLETRAS. Esses gêneros encontram-se listados no Gráfico 1 a seguir:

Gráfico 1: Quadro geral de gêneros sugeridos ou trabalhados 


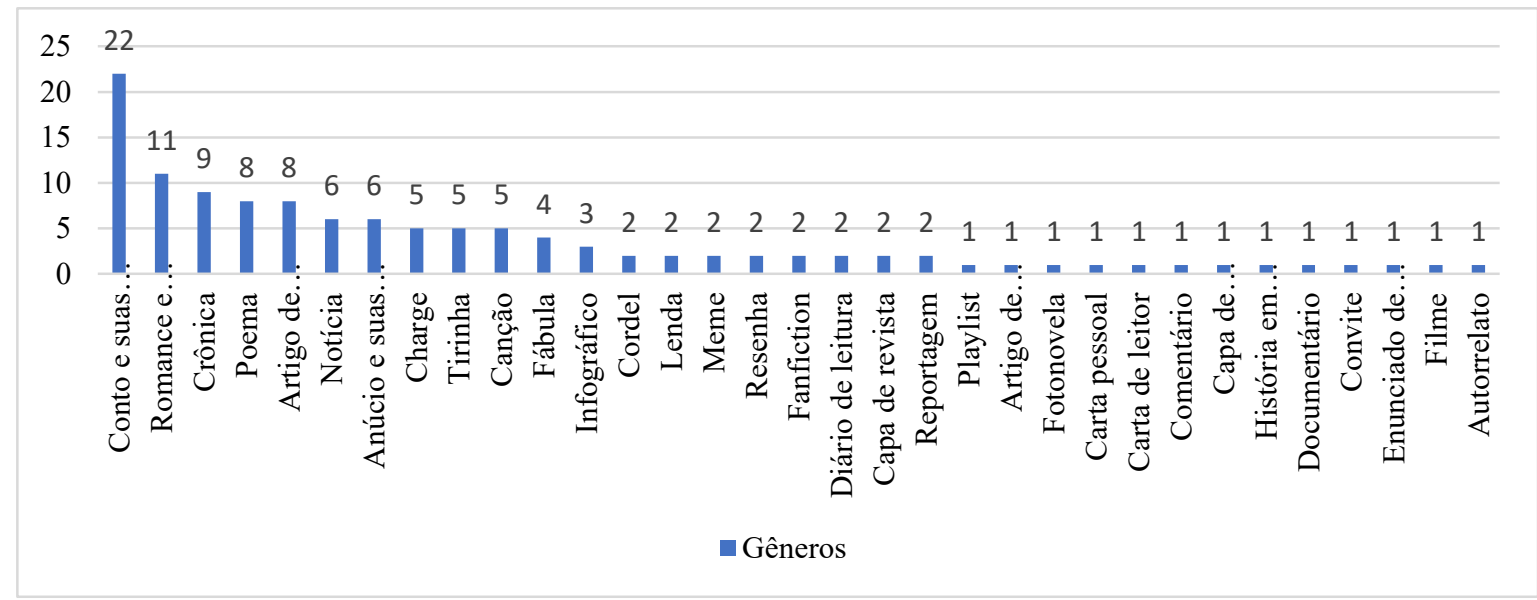

Fonte: Elaboração própria

O Gráfico 1 ilustra a variedade de gêneros textuais contemplados, individualmente ou em associação (ou seja, mais de um gênero), nas propostas de ensino de leitura desenvolvidas no programa. São gêneros oriundos de diversos domínios de circulação: o literário, o publicitário, o midiático, o jornalístico, o instrucional, o lazer e o interpessoal. Nesses domínios discursivos, alguns gêneros parecem mais apropriados para o ensino de leitura e outros para o ensino da escrita. É que, conforme lembra Coscarelli (2007), há gêneros para ler e gêneros para escrever, para ouvir, para falar. No caso dos gêneros literários como poema, por exemplo: não precisamos necessariamente saber escrevê-lo, mas precisamos saber ler textos pertencentes ao gênero. A seleção realizada pelos professores na elaboração das propostas de intervenção parece considerar muito bem esse aspecto e, acertadamente, prioriza gêneros apropriados ao trabalho com o ensino de leitura. Referente ao domínio literário, o conto, o romance, a crônica, o poema, a fábula, o cordel e a lenda são gêneros muito adequados ao trabalho com a leitura na escola. Por isso, a recorrência significativa desses gêneros literários nas propostas de intervenção: 41,3\% dos gêneros trabalhados pertencem ao domínio literário.

Por outro lado, a respeito ainda desse domínio, convém esclarecer que o ensino de leitura não deve se limitar ao trabalho com gêneros literários. Ainda que não se possa dizer isso do quadro de propostas apresentado, visto a presença de gêneros de diversos outros domínios, não podemos ignorar a predileção pelos gêneros literários, maiormente os gêneros literários canônicos. De fato, eles representam significativamente o maior universo das propostas de ensino de leitura realizadas no PROFLETRAS. Se, por um lado, esse dado testemunha uma tradição no ensino de leitura nas escolas, por outro, faz-lhe reforço: o ensino de leitura nas escolas está 
profundamente relacionado ao trabalho com a literatura. O contato com o texto literário é substancial para a formação integral dos alunos, até porque, como poeticamente lembra Coutinho (2014, p. 14), "através das obras literárias, tomamos contato com a vida, nas suas verdades eternas, comuns a todos os homens e todos os lugares, porque são as verdades da mesma condição humana”. Ora, a literatura contribui muito sensivelmente para o processo de humanização dos sujeitos, todavia, ainda assim, a escola não deve restringir o ensino da leitura aos gêneros canônicos literários, mas considerar os diversos gêneros textuais utilizados nas mais variadas situações de interação.

Não obstante, há que se levar também em conta um aspecto singular bem observado por Marcuschi (2008, p. 196): "há domínios discursivos mais produtivos em diversidade de formas textuais e outros mais resistentes". Esse dado explica a variação de gêneros textuais da mídia nas propostas de intervenção desenvolvidas no PROFLETRAS para o ensino de leitura. Esse domínio é numerosamente produtivo em diversidade de gêneros textuais, dada a função, especialmente, da influência de recursos de tecnologias digitais. É o caso de gêneros como o meme, a fanfiction e a capa de página do Facebook: eles nascem nos espaços digitais e apenas existem em função desses espaços - ainda que possam ser transpostos didaticamente para a sala de aula. O ensino de leitura a partir desses gêneros textuais do domínio midiático - numa interface com o digital - apresenta-se como muito produtivo, conforme revelam as propostas de intervenção desenvolvidas no âmbito do PROFLETRAS. Na verdade, trabalhar com esses gêneros é uma recomendação institucional, segundo a Base Nacional Curricular Comum (BNCC): "as práticas de linguagem contemporâneas não só envolvem novos gêneros e textos cada vez mais multissemióticos e multimidiáticos, como também novas formas de produzir, de configurar, de disponibilizar, de replicar e de interagir" (BRASIL, 2017, p. 68). Por isso, "contemplar de forma crítica essas novas práticas de linguagem e produções" possibilita "fomentar o debate e outras demandas sociais que cercam essas práticas e usos" (BRASIL, 2017, p. 67).

Marcuschi (2008) arregimenta essa predileção por determinados gêneros a uma dimensão cultural: "há culturas em que a situação se inverteria totalmente" ( $p$. 197). Ora, a atual sociedade brasileira caracteriza-se pelo grafocentrismo e pela influência exacerbada dos recursos digitais na comunicação. Não é sem razão que a maioria dos gêneros textuais selecionados para as propostas de trabalho com o 
ensino de leitura no PROFLETRAS pertença aos domínios literário e midiático. Claro que o fato de se constituírem de propostas de trabalho com a leitura também exerce influência sobre a escolha desses gêneros, conforme Coscarelli (2007). De toda maneira, o trabalho com alguns gêneros em específico reforça essa dimensão cultural que estimula a seleção dos gêneros adotados nas propostas: é o caso do cordel ou do conto amazônico, por exemplo - o primeiro selecionado para uma proposta de intervenção aplicada em uma escola do estado da Paraíba e o segundo do estado do Pará. Os contextos geográficos, nesses casos, foram determinantes para a escolha dos gêneros organizadores das propostas.

A variedade de tipos de gêneros textuais apresentada no Gráfico 2 a seguir justifica-se pela condição dos sujeitos que desenvolveram as propostas de intervenção: professores de língua portuguesa na Educação Básica, com formação inicial em cursos de licenciatura em Letras. Esses professores, ao menos minimamente, conhecem dispositivos teórico-metodológicos que orientam o trabalho com a variedade de gêneros textuais no ensino de língua portuguesa. Nesse sentido, já a formação inicial ou até mesmo as experiências didáticas antes vivenciadas em sala de aula por esses professores influenciam na seleção dos gêneros adotados nas propostas de ensino de leitura desenvolvidas no PROFLETRAS.

De maneira semelhante, também a condição de professor de língua portuguesa influencia na escolha da turma e do ano escolar onde se desenvolveram as propostas. Conforme já dissemos, o público-alvo do PROFLETRAS constitui-se de professores de língua portuguesa do Ensino Fundamental, portadores de diploma de curso de Letras. Por isso, o trabalho de conclusão do curso deverá desenvolver-se a partir de determinado problema da realidade escolar e/ou da sala de aula do mestrando referente ao ensino e à aprendizagem de língua portuguesa no Ensino Fundamental. Assim sendo, nesta radiografia, buscamos identificar que anos escolares são mais recorrentemente selecionados para a aplicação das propostas de intervenção de ensino de leitura no programa. Esse dado encontra-se apresentado no Gráfico 2 abaixo:

Gráfico 2: Anos escolares de turmas onde se desenvolveram as propostas 


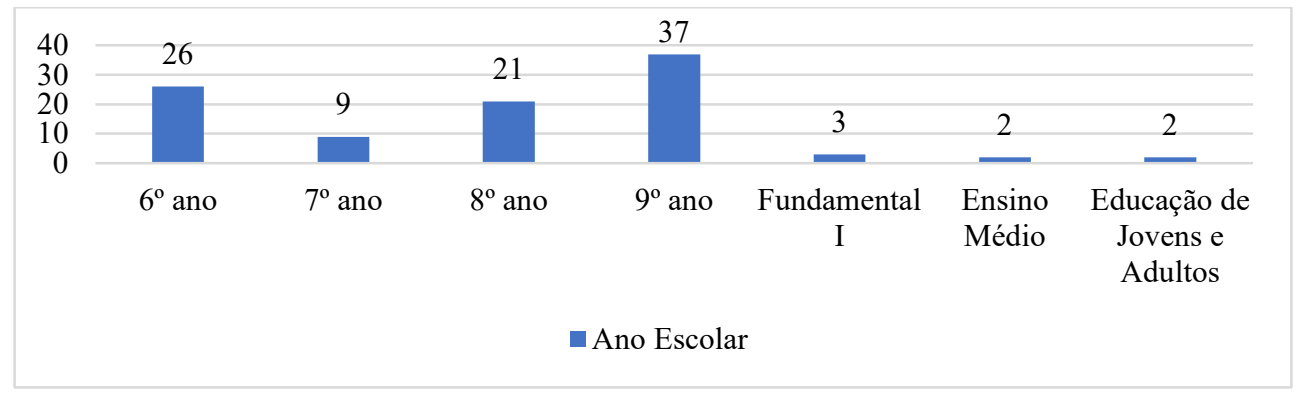

Fonte: Elaboração própria

Como visivelmente se percebe numa leitura geral do Gráfico 2, as turmas de anos escolares que mais preferencialmente são selecionados pelos professores para a aplicação de suas propostas de intervenção são aquelas que marcam o início e o término do segundo momento do Ensino Fundamental, ou seja, o $6^{\circ}$ e o $9^{\circ}$ anos. Das 100 dissertações que formam o nosso corpus de análise, pelo menos $63 \%$ delas apresentam propostas de intervenção que foram desenvolvidas em turmas desses anos escolares. As demais referem-se a propostas realizadas em turmas do $7^{\circ}$ e $8^{\circ}$ anos, turmas dos anos iniciais do Ensino Fundamental, turmas do Ensino Médio e turmas de alunos da modalidade de Educação de Jovens e Adultos. Esses dados devem revelar algumas incongruências referentes às preferências desses professores na escolha de turmas para o desenvolvimento das propostas de intervenção de suas pesquisas de mestrado.

No que diz respeito às turmas de $6^{\circ}$ ano do Ensino Fundamental, tradicionalmente, os alunos encontram dificuldades de adaptação ao novo ciclo de aprendizagem, considerando as mudanças que se apresentam: o gerenciamento de disciplinas novas no currículo (fragmentadas) e de professores específicos para cada uma delas, a nova rotina de sala de aula (maior número de conteúdos e de atividades), a redução de atividades lúdicas, um maior distanciamento interpessoal entre professores e alunos, dentre outras. Dessa maneira, ainda que se trate de um mesmo nível de ensino, essa passagem de uma série para outra, nesse caso, é tão marcada que constitui mesmo uma transição. Todas essas rupturas podem afetar consideravelmente a aprendizagem dos alunos no $6^{\circ}$ ano. A preocupação com esse nível de aprendizagem dos alunos, portanto, não é gratuita, mas leva em conta todos esses fatores pedagógicos que interferem na sua organização.

Por outro lado, as turmas do $9^{\circ}$ ano caracterizam-se por marcarem o término deste ciclo de aprendizagem fundamental. Neste caso, a preocupação maior é 
assegurar que o aluno, ao final do Ensino Fundamental, se encontre preparado para o início do novo ciclo, o Ensino Médio. Ademais, os alunos matriculados em turmas deste ano escolar são submetidos a diversos exames externos organizados pelo Sistema de Avaliação da Educação Básica (SAEB), que buscam avaliar o índice de desenvolvimento dos estudantes. Os resultados desses exames, associados a avaliações internas, indicam, pois, a qualidade (ou as deficiências) do ensino ofertado pelas escolas e oferecem subsídios para o monitoramento e a elaboração de propostas de intervenção. Como há um grande marketing na divulgação desses resultados, garantir que os alunos apresentem bom rendimento é fundamental para a construção de uma imagem positiva da escola. Para isso, investir nas turmas de alunos do $9^{\circ}$ ano é uma condição necessária. Sendo assim, a preferência dos professores por desenvolverem as propostas de intervenção de ensino de leitura em turmas desse ano escolar pode ser justificada em função desses aspectos.

Em síntese, a maioria das propostas de intervenção foram desenvolvidas nos últimos anos do Ensino Fundamental, conforme sugerem as diretrizes reguladoras do programa. Todavia, ainda de acordo com o Gráfico 2, também foram desenvolvidas propostas nos anos iniciais do Ensino Fundamental, no Ensino Médio e em turmas de Educação de Jovens e Adultos. Há algumas explicações a se fazer nesses casos: primeiro, o trabalho com o ensino de leitura nessas turmas é tão imperativo e relevante quanto nas demais turmas de anos escolares finais do Ensino Fundamental. Além disso, por exemplo, no Ensino Médio, os alunos encontram-se com elevados níveis de defasagem em competências leitoras, de acordo com dados oriundos do ENEM, o que é resultado de um efeito cascata, ou seja, de deficiências decorrentes dos anos finais do Ensino Fundamental. A modalidade de Educação de Jovens e Adultos tem sofrido historicamente com diversos problemas relacionados à aprendizagem dos alunos, notadamente no que se refere ao ensino de leitura.

Em segundo lugar, alguns professores desenvolveram propostas de intervenção de modo articulado entre duas turmas de anos escolares distintos, por exemplo, uma turma de $6^{\circ}$ ano do Ensino Fundamental e outra turma do $1^{\circ}$ ano do Ensino Médio. De igual forma isso ocorreu com turmas dos anos iniciais do Ensino Fundamental e turmas da modalidade de Educação de Jovens e Adultos. Essas articulações mostraram-se muito produtivas, seja porque a reflexão acerca do ensino de leitura ocorre em níveis de ensino distintos, o que possibilita comparar realidades díspares para se compreenderem as dificuldades relativas a essa prática, seja porque 
se consegue verificar a sequencialidade no ensino da língua portuguesa entre os níveis de ensino da Educação Básica, seja porque amplificam-se as contribuições de uma proposta interventiva para um maior número de estudantes da Educação Básica. Em todo caso, é importante apontar que não se trata de um descumprimento da regulamentação do programa, mas de tentativa de rearranjos produtivos.

Por outro lado, não é sem razão, pois, a predileção dos professores em suas propostas de intervenção por gêneros como o conto e o artigo de opinião, por exemplo. O trabalho com esses gêneros nos anos finais do ensino fundamental é recomendado por documentos oficiais reguladores do ensino no país, como os PCN e a BNCC - esse último documento, especificamente, sugere que esses gêneros representativos do campo artístico-literário e do midiático jornalístico são relevantes para o desenvolvimento das habilidades de leitura e de produção de textos.

Outra intenção nossa neste trabalho foi identificar e descrever as abordagens teórico-metodológicas que serviram de alicerce à elaboração e aplicação das propostas de intervenção no âmbito do PROFLETRAS. Até mesmo por influência de um regime educacional que recomenda o cumprimento das orientações e normas reguladoras do ensino, as propostas aqui analisadas seguem de perto os PCN e a BNCC, além de outros documentos locais como os projetos político-pedagógicos das escolas onde as propostas de intervenção foram desenvolvidas. Todavia, diversas críticas já foram direcionadas para esses documentos, fundamentalmente para o caráter genérico na proposição de orientações para o ensino da língua portuguesa. Nos PCN, por exemplo, a falta de referência explícita sobre como os professores devem proceder no trabalho com o texto em sala de aula, de alguma maneira, questiona a sua validade didático-metodológica. Por outro lado, também a BNCC, compreendida como aprimoramento curricular dos parâmetros, tem sido objeto de crítica por parte de alguns linguistas e professores, notadamente no que se refere ao minucioso detalhamento da estrutura curricular do ensino de língua portuguesa. Reelaborada a partir de um aparato terminológico e conceitual, a rede intrincada de informações do documento mais parece complexificar a compreensão a respeito dos processos de ensino e de aprendizagem da língua portuguesa do que promover, de fato, ressonâncias no currículo escolar. Entretanto, não é nosso interesse valorar a despeito de limitações desses documentos, mas somente apontar uma necessidade enfrentada pelos professores de língua portuguesa da escola básica brasileira: a falta de dispositivos didático-metodológicos que apresentem bases mais sólidas e 
orientações objetivas sobre o ensino. Por isso, inclusive, o empreendimento de linguistas e professores em elaborar, a partir de suas vertentes teóricas de pesquisa, propostas de ensino possíveis de serem aplicadas na escola pública brasileira.

Diversos desses procedimentos já estão relativamente estabilizados na prática pedagógica de ensino de língua portuguesa, conforme atesta a literatura vigente. $O$ exame sobre as propostas de intervenção desenvolvidas no PROFLETRAS também evidencia a produtividade dessas abordagens:

Gráfico 3: Abordagens teórico-metodológicas em propostas do PROFLETRAS

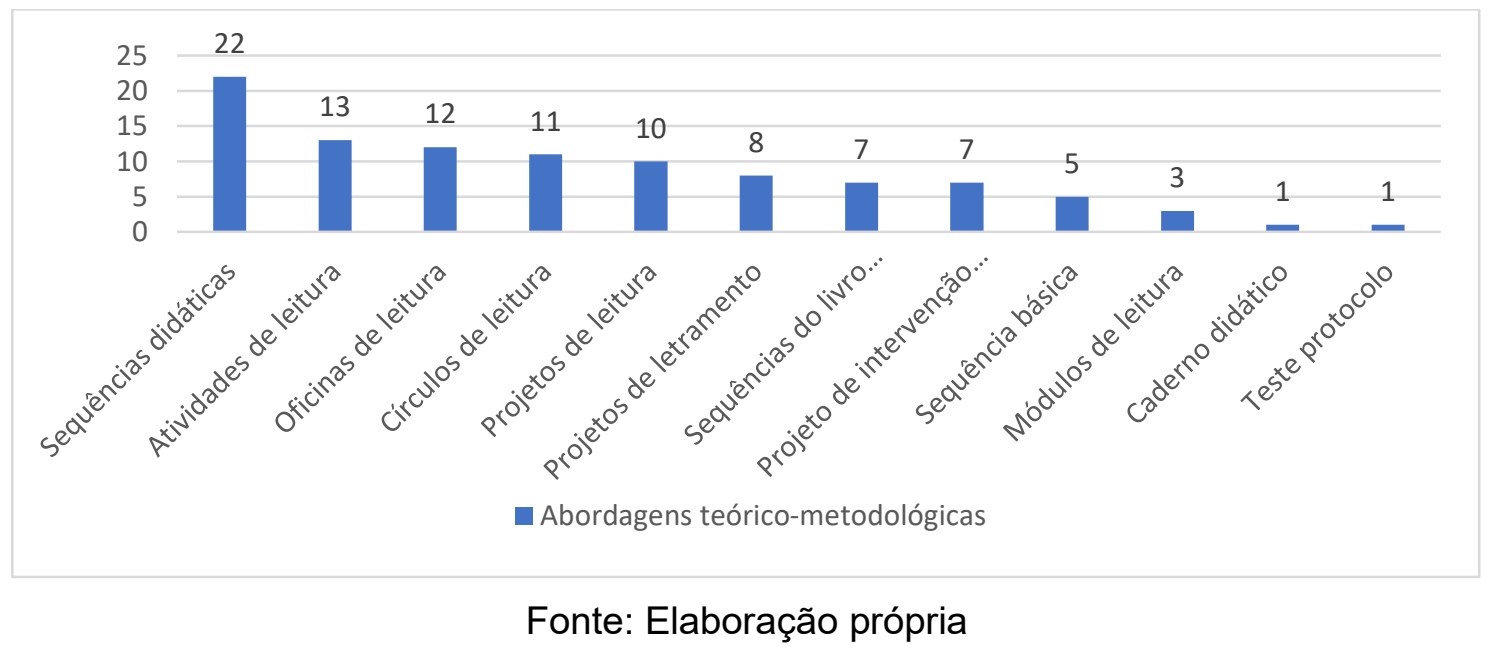

A leitura do Gráfico 3 revela a diversidade de abordagens teóricometodológicas adotadas nos trabalhos desenvolvidos no PROFLETRAS. Ressalta-se o destaque que tem a proposta de sequências didáticas, procedimento elaborado por um grupo de professores pertencentes ao Departamento de Didáticas de Línguas da Faculdade de Psicologia e Ciências da Educação da Universidade de Genebra, notadamente Joaquim Dolz, Bernard Schneuwly e Michéle Noverraz. O modelo desenvolvido por esses professores envolve um conjunto de atividades escolares organizadas sistematicamente pelo professor em torno de um determinado gênero, com a finalidade de favorecer ao aluno o seu domínio efetivo em situações de comunicação. A proposta foi amplamente difundida no contexto escolar brasileiro, sobretudo após a publicação dos PCN, quando se recomendou oficialmente que o ensino de língua portuguesa deveria ser centrado nos gêneros do discurso - ou gênero textual, já que não nos interessa aqui fazer distinção conceitual. De fato, a difusão desse modelo de ensino tornou-se bastante acentuada na escola pública brasileira, porque permite tanto o trabalho com alguma habilidade específica, como 
no caso do ensino de leitura, por exemplo, como também de várias habilidades, a partir de atividades desenvolvidas nos variados módulos possíveis. Em todo o caso, o gênero é sempre ponto de partida e de chegada.

Além disso, merecem destaque metodologias como a oficina de leitura e os projetos de leitura. No primeiro caso, não há necessariamente uma única metodologia padrão que normatize a organização do trabalho pedagógico em sala de aula, mas as intervenções apresentam diversos modos de organização do trabalho com a leitura a partir de tarefas que articulam vivências e experiências práticas pelos participantes. Por isso, inclusive, há grande flutuação nos trabalhos: algumas vezes, a proposta se constitui de um conjunto de oficinas, que, por não poderem ser aplicadas isoladamente, formam como que um projeto de leitura - ainda que não sejam assim nomeadas; outras delas organizam-se em módulos, em um conjunto de atividades com objetivos específicos determinados; outras, ainda, são organizadas em unidades temáticas que, articuladas, constituem uma oficina. Em todos esses casos, o desenvolvimento de habilidades e de competências a partir de determinadas estratégias de leitura é central. Diferentemente da metodologia das sequências didáticas, as oficinas não focalizam necessariamente um único gênero, mas podem, também, articular gêneros de tipos variados, já que o propósito não reside só em desenvolver habilidades de leitura inerentes a um gênero, mas sim competências que são necessárias ao trabalho com a leitura em situações do cotidiano. Assim, há um grande esforço do professor também na própria elaboração do instrumento metodológico adotado, que não se deve limitar à experiência em sala de aula, mas, com devidas adaptações, deve apresentar condições de replicação noutros espaços.

Os projetos de leitura são bem mais extensos que as oficinas pedagógicas e, por vezes, já estão em curso nas escolas ou são elaborados pelos professores com duração que excede o trabalho de intervenção desenvolvido, tendo muito mais um caráter de programa nas escolas. A sua organização metodológica prevê não somente tarefas factuais, mas sim um conjunto de ações de promoção à leitura que demandam longa duração e até mesmo algum investimento financeiro. Nesse sentido, ainda que a proposição do projeto seja feita pelo professor, a articulação com outros atores da escola, principalmente os gestores, pode ser fundamentalmente necessária. De igual modo, grande parte dos projetos de leitura das propostas de intervenção do PROFLETRAS se caracteriza pelo caráter interdisciplinar, ainda que o professor de língua portuguesa coordene as ações. 
Os círculos de leitura e os projetos de letramento apresentam uma metodologia já mais previamente definida. Os círculos, utilizados prioritariamente para o trabalho com a literatura, guiam-se por uma metodologia - alguns autores do Brasil, como Cosson (2014), empenharam-se bastante em sua sistematização - que pode ser sintetizada em três passos: preparação, execução e avaliação. A organização desse trabalho pode se dar em torno de um texto (geralmente, um gênero literário) ou um tema ao qual mais de um texto (de mais de um gênero) é associado. Sendo assim, os círculos são espaços de contato com o texto e de desenvolvimento de experiências éticas e estéticas pelos seus participantes. Em algum ponto, eles lembram os círculos de cultura do educador Paulo Freire, pelo fato de buscar o compartilhamento de informações e a construção conjunta do conhecimento - alguns trabalhos, inclusive, retomam o autor, numa tentativa de estabelecer articulações no desenvolvimento da intervenção. De maneira geral, os trabalhos já desenvolvidos no PROFLETRAS têm atestado as contribuições que essa abordagem pode apresentar para o ensino de leitura na escola. Há que se cuidar, todavia, para que o trabalho com a leitura não se limite à literatura, como se o texto literário fosse o único possível para tal.

Já os projetos de letramento, frequentemente adotados em propostas de ensino da língua portuguesa para o trabalho com a leitura e a escrita, originam-se a partir de dada questão social real e constituem práticas sociais de linguagem. No caso das propostas do PROFLETRAS, há sempre uma problemática que motiva os professores na realização de um trabalho interventivo que visa modificar a situação inicial. $O$ projeto envolve conjunto de atividades relacionadas à leitura de textos que circulam efetivamente na sociedade, que apresentam funções sociais reais. $O$ trabalho com textos concretos é um traço distintivo desse tipo de metodologia. As atividades planejadas tanto podem focalizar um gênero só, como podem estar organizadas em torno de vários textos de gêneros distintos, mas que, de algum modo, realizam uma prática social. Metodologicamente, o projeto pode ser sistematizado em unidades, módulos, oficinas, etapas, enfim, ou outra forma de divisão, mas todas essas etapas dirigem-se para a consecução de uma prática ou de práticas sociais. Os objetivos das propostas de intervenção que adotam essa metodologia não são voltados apenas ao desenvolvimento de habilidades e competências de leitura, mas ao seu emprego em situações reais de uso.

Outra abordagem adotada em alguns trabalhos do PROFLETRAS foi a sequência básica de letramento literário. Esse procedimento foi sistematizado no 
Brasil por Cosson (2016), sendo, por isso, semelhante aos círculos de leitura literária. Uma sequência básica se organiza em quatro etapas: motivação, introdução, leitura e interpretação. Sendo mais preferencialmente adotado no trabalho com a literatura, esse procedimento visa ao trabalho com o texto literário em sala de aula a partir da sensibilização do aluno para a leitura. O texto objeto de uma sequência, geralmente, é um gênero literário, como o conto, a crônica ou o romance, mas a leitura é sempre tomada como processo, então, não se limita ao ato mecânico, mas todo o conjunto de atividades e práticas que envolvem o processo.

Além dessas metodologias mais frequentemente adotadas nos trabalhos que foram desenvolvidos no PROFLETRAS para o ensino de leitura, em outros casos, os professores utilizaram sequências de atividades do livro didático, a produção de cadernos didáticos e de atividades de leitura especificamente elaboradas por ocasião de aplicação da proposta de intervenção, módulos de leitura (unidades didáticas com conjuntos de textos e tarefas de compreensão e interpretação) e teste de protocolo (utilizado para identificar e trabalhar dificuldades de leitura). Esses procedimentos não possuem necessariamente influência de uma abordagem teórica, mas congregam fundamentos de variadas correntes, especialmente dos estudos da linguagem (com destaque para a Linguística Aplicada, em suas abordagens distintas), da Pedagogia, das ciências da cognição e da Psicologia.

Em todos os casos, há uma avaliação sempre positiva em relação às propostas que foram desenvolvidas, já que os trabalhos ressaltam as contribuições que as metodologias adotadas apresentaram para o ensino de leitura na escola. Especificamente, de modo geral, os trabalhos apontam mudanças significativas e potenciais no perfil de leitor dos alunos, no desenvolvimento de experiências com a leitura, no desenvolvimento do hábito e prazer de ler, nas rotinas das escolas e de bibliotecas escolares, na ampliação de acervos, enfim. Além disso, como resultado dessas propostas, os professores elaboram produtos didáticos variados, que são disponibilizados nos sites e repositórios dos programas e publicados em livros, artigos, periódicos, cadernos didáticos etc. Esses produtos apresentam a proposta de intervenção aplicada ou uma síntese dela, que pode ser replicada e adaptada em escolas por outros professores.

\section{Considerações finais}


As reflexões desenroladas nesse artigo permitiram-nos construir uma radiografia das propostas de intervenção no ensino de leitura desenvolvidas no PROFLETRAS. Este levantamento foi realizado a partir de um rigor metodológico que assegura a veracidade das informações apresentadas. Os resultados apontam os impactos que o desenvolvimento das propostas de intervenção apresenta para o ensino de língua portuguesa na Educação Básica, notadamente no Ensino Fundamental da escola pública. Na verdade, o fato de essas propostas serem desenvolvidas exatamente na escola pública justifica per se a importância relevada do programa e dos trabalhos desenvolvidos pelos professores. De igual maneira, os produtos didáticos oriundos das propostas são fundamentos didático-pedagógicos que podem contribuir sobremaneira com outros professores, inclusive que não tiveram opção de realizar uma formação continuada stricto sensu. A esse respeito, todavia, parece-nos ser preciso investir muito mais fortemente na divulgação desses materiais, para que eles alcancem, de fato outras escolas públicas, cujos professores ainda se encontram distantes dos centros universitários.

Relativo às repercussões do programa no ensino de leitura no Brasil, os dados aqui levantados apontam para avanços importantes no quadro atual. Ora, foram desenvolvidos 671 trabalhos sobre ensino de leitura no período de 2015-2019. Sendo assim, um número expressivo de alunos em todo o país foi de alguma maneira impactado com uma proposta de ensino de leitura diferenciada, de onde se supõe que as experiências de leitura também foram alteradas. Todavia, é necessário um maior prazo para que avaliações nacionais ou internacionais possam mensurar mais precisamente os efeitos dessas propostas no quadro de leitores do país. De todo modo, o que se pode assegurar é que esse é um dos caminhos possíveis para que a situação de leitura do Brasil possa ser revertida. É inquestionável que investimentos já realizados no programa devem ser mantidos e, sobretudo, intensificados para que as universidades possam continuar ofertando turmas de mestrado profissional e os professores da educação básica tenham condições de frequentá-las.

\section{Referências}

ANUÁRIO. Anuário Brasileiro da Educação Básica - 2020. São Paulo: Todos pela Educação; Editora Moderna, 2020. 
BRASIL. Ministério da Educação (MEC). Base Nacional Comum Curricular. Brasília, 2017.

BARDIN, Laurence. Análise de conteúdo. São Paulo: Edições 70, 2011.

COSCARELLI, Carla Viana. A produção de gêneros textuais. In: Veredas - Ensino, v.2, 2007, p. 78-86.

COSSON, Rildo. Círculos de Leitura e Letramento Literário. São Paulo: Contexto, 2014.

COSSON, Rildo. Letramento literário: teoria e prática. 2. ed. São Paulo: Contexto, 2016.

COUTINHO, Afrânio. Notas de teoria literária. 14. ed. Rio de Janeiro: Civilização Brasileira, 2014.

FREIRE, Paulo. A importância do ato de ler. em três artigos que se completam. São Paulo: Paz e Terra, 2006.

INSTITUTO PRÓ-LIVRO. Retratos da leitura no Brasil - 2019. 5. ed. 2020.

MARCUSCHI, Luiz Antônio. Produção textual, análise de gêneros e compreensão. São Paulo: Parábola, 2008.

TODOROV, Tzvetan. A literatura em perigo. Tradução de Caio Meira. Rio de Janeiro: DIFEL, 2009. 